\title{
Apprehension, Topic Variety, and Proficiency in Writing of
}

\section{Indonesian EFL Students}

\author{
Bambang Yudi Cahyono ${ }^{1}$, Rizky Amelia ${ }^{2 *} \&$ Ira Mutiaraningrum $^{2}$ \\ ${ }^{1}$ English Department, Universitas Negeri Malang, East Java, Indonesia \\ ${ }^{2}$ Graduate Program in English Language Teaching, Universitas Negeri Malang, East Java, Indonesia \\ * Rizky Amelia, E-mail: melsmasix@gmail.com
}

\begin{abstract}
This study examined the relation between Indonesian EFL students' apprehension and proficiency in writing, students 'proficiency in writing across apprehension levels, and students 'proficiency in writing across topic variety. It involved 52 EFL students of the English Deparment of an Indonesian university. The students were assigned to write opinion essays in three different topics: general, personal, and academic topics. They were also asked to complete a questionnaire which was used to elicit their apprehension scores. The results of the analysis show that (1) there was no significant relation between students' apprehension and their proficiency in writing, (2) there was no significant difference in the proficiency in writing between low apprehension students and medium apprehension students, and (3) there were significant differences between students ' proficiency in writing general topics and academic topics and between their proficiency in writing personal topics and academic topics. This study suggests that EFL teachers of writing should not consider students' apprehension levels as a factor that affects students' proficiency in writing in a negative way. In addition, when assigning students to write academic topics, EFL teachers are recommended to provide some strategies to help them write more easily.
\end{abstract}

\section{Keywords}

apprehension, topic variety, proficiency in writing, EFL students

\section{Introduction}

Writing is commonly considered the most difficult skill to master among the four language skills, namely listening, speaking, reading, and writing, due to the involvement of various writing components (Cahyono \& Widiati, 2011, p. 69; Harmer, 2004, p. 8; Richards \& Renandya, 2002, p. 303). The components of writing which are commonly included in the assessment of proficiency in writing are content, organization, vocabulary, language use, and mechanics (Hartfiel et al., 1985; Weigle, 2002). The claim that writing is difficult, especially for Indonesian English as a Foreign Language (EFL) students, has encouraged us to examine some of the factors causing the difficulty in writing. It has been known that basically there are two major factors which determine the difficulties in learning a foreign 
language: linguistic and non-linguistic factors (Amiri \& Ghonsoonly, 2015). Linguistic factors deal with difficulties caused by lexical or syntactical aspects of language. In writing, linguistic factors are likely to affect the components of vocabulary, language use, and mechanics, especially spelling.

Non-linguistic factors cover a number of categories, three of which are frequentlymentioned: cognitive, affective, and metacognitive (Amiri \& Ghonsoonly, 2015; Oxford, 1990). In writing, the non-linguistic factors tend to affect the components of content and organization. In fact, researchers are aware of the importance of these factors and they attempt to investigate them. Khezrlou (2012) scrutinized the use of cognitive and metacognitive strategies in learning a second language and Henter (2014a, 2014b) examined how affective factors influence learning a foreign language. In the area of writing in particular, Ong and Zhang (2013) investigated the effects of the manipulation of cognitive processes on EFL writers' text quality. However, non-linguistic factors remained to be questioned, especially regarding whether these factors come to a person individually or to a number of individuals. For example, it is still inconlusive whether or not anxiety as an affective factor is experienced by a few students or by a bigger number of students (Daly \& Miller, 1975). Many studies on non-linguistic factors have been carried out (for example, Henter, 2014; Jain \& Sidu, 2013; Asmari, 2013; Khezrlou, 2012). However, many of these studies focus on language learning in general. Therefore, we are interested in examining how non-linguistic factors, particularly apprehension (an affective factor) and topic variety (a cognitive factor) relate to proficiency in writing.

Apprehension refers to a trait that makes people anxious in doing something. Anxious feelings lead people to poor learning outcomes (Lightbown \& Spada, 2013). Thus, students' apprehension in writing is likely to affect their proficiency in writing: the higher the apprehensive feeling, the lower the proficiency in writing (Daly \& Miller, 1975). The influence of apprehension on language learning can be explained by Krashen's affective filter hypothesis. According to Krashen, as restated by Allwright (1998), "the learner's brain would filter available input, letting in to the central acquisition process only those items that were affectively available to the learner" (p. 5). Because apprehension is an unfavorable feeling toward something, an apprehensive or anxious person's brain filters out input and this hinders language acquisition (Lightbown \& Spada, 2013). In his review of research report on the role of anxiety, Ellis (2001) also concludes that anxiety affects language learning, however it "contributes in differing degrees in different learners" (p. 493).

A number of studies have reported how writing apprehension relate to writing achievement (e.g., Asmari, 2013; Choi, 2013). Asmari (2013) investigated the correlation between writing strategies, apprehension, and achievement among 198 Saudi university students. The results of that study showed that writing apprehension was related to writing achievement. The less anxious students used more writing strategies than the more anxious students. Asmari's study supported Al-Sawalha and Chow's (2012) study which found that apprehension in writing affected the frequency of strategy use and type of strategy use. Choi (2013) investigated the foreign language anxiety of Korean students in second language writing anxiety and performance of 26 senior high school students. It was revealed that there 
was no significant correlation between anxiety and writing performance as observed, but students with high anxiety tend to show poor performance on the writing. This is also the case of apprehension in writing to a higher academic writing work. For example, Ayodele and Akinlana (2012) examined the relationship between writing apprehension and undergraduates' interest in dissertation among 2400 Nigerian undergraduate students. The results of that study showed that writing apprehension correlated with undergraduates' interest in dissertation writing. In the same line, apprehension in writing was found to have significant relation to academic levels (Bobanovic, 2016). Thus, apprehension in writing is likely to correlate negatively with proficiency in writing various types of academic work and the use of strategies in writing.

Current research reports on the role of topic variety showing differing results. Lubold, Forbes and Steveson (2016) reported the significant effect of students' selected topics on their writing fluency. The effect of topic variety on writing fluency in Lubold et al.'s study might be caused by students' preferences and prior knowledge of their own selected topics. Therefore, in order to know its effect, in this study, topic variety is understood as different topics that are assigned to the students for particular writing tasks, thus minimizing the influence of students' preference and prior knowledge. Ji (2011) examined the quality of students' essays on two different topics: a general topic (an essay on Education) and a more focussed topic (an essay on Golf Course). The result of Ji's study showed that the students wrote better in the essay with the more focussed topic. Ji explained that students could write better in the latter topic because they were familiar with the topic and the topic is more throught-provoking than the former one. In her research on Indonesian EFL students' writing performances across general, personal, and field-discipline topics, Nugraheni (2016) found that there was no significant difference in students' performances across the three kinds of topics.

It is worth noting that there has been no research investigating the possible relationship between apprehension, topic variety, and proficiency in writing. Therefore, this study aimed at examining the relation of apprehension, topic variety, and proficiency in writing of Indonesian EFL students. The research questions are formulated as follows:

1) Is there any relation between Indonesian EFL students' apprehension and proficiency in writing?

2) Is there any difference between Indonesian EFL students' proficiency in writing across apprehension levels?

3) Is there any difference among Indonesian EFL students' proficiency across topic variety?

\section{Method}

This research aims to find out the relationship between Indonesian EFL students' apprehension, topic variety, and proficiency in writing. It involved 52 students who attended Argumentative Writing course offered in the English Department of Universitas Negeri Malang, one of the prominent universities in Indonesia. The students were from two classes: Class A (26 students) and Class B (26 students), both consisting of male and female students. The Argumentative Writing course had 4 credits and lasted for 
16 weeks, comprising 32 meetings. It is one of the three writing courses taught in the English Department. The other two courses are Paragraph Writing course which aims at helping the students to write good paragraphs and Essay Writing course which is intended to train students to write essays of five types of development: examplification, comparison and contrast, classification, process analysis, as well as cause and effect analysis.

In the Argumentative Writing course students were taught to write essays of two types: opinion essay and argumentative essay. The course used materials from three chapters of three different textbooks: “Argumentative Essays" (Oshima \& Hogue, 2006, Chapter 9, pp. 142-160), "Opinion essays" (Oshima \& Hogue, 2007, Chapter 10, pp. 168-180), and "The Argumentative Essay" (Smalley, Ruetten, \& Kozyrev, 2001, Chapter 12, pp. 275-298). In writing an opinion essay, students were required to state their opinions and provide reasons from one side, namely their own (Oshima \& Hogue, 2007, p. 169). In contrast, in writing an argumentative essay, the students were required to take a stand and provide arguments regarding the topic and at the same time refute arguments from the opponents (Smalley et al., 2001, pp. 282-284).

For the purpose of the study, students were asked to write opinion essays. Opinion essays were chosen because the reasons used to support the opinions come from the students and this might relate to their apprehension in determining reasons for their opinions. They were asked to write three different topics: general, personal, and academic topics. Four sub-topics were given to the students for each topic category. They are Arrange Marriage, Anti-smoking Laws, Telephone Use while Driving, Cencorship (General); Why I Like My Hobbies, Why I Like My Favorite Food, Why I Like a Certain Person, What I Want to be (Personal); and English for Taxi Driver, English Movies for English Department Students, English as a Medium of Instruction in Non-English Departments, English for Primary School Students (Academic).

Before students were assigned to write opinion essays for the three topics, they were given theoretical explanations about how to write opinion essays. Then, they were asked to write each of the three topics in one week: general topics in the first week, personal topics in the second week, and academic topics in the third week. Thus, it took one week to complete each of the writing products. The process of developing ideas and drafting was started in the classroom, while the finalizing and typing the products were assigned as homework.

From the opinion essay writing assignments, 52 essays for each topic were collected, thus a total of 156 essays for the three topics altogether. Then, the essays were scored by using scoring rubric developed by Hartfiel et al. (1985) called "ESL Composition Profile". This scoring rubric has five components of writing with various rating scales: content (30\%), organization (20\%), vocabulary (20\%), language use (25\%), and mechanics (5\%). In the process of scoring, each of the essays was scored by two raters. The distribution of the essays scored is shown in Table 1. Prior to the actual scoring, the raters practiced scoring for 10 essays, comparing the scores of the essays and discussing the results to achieve similar scores. When extreme differences were found in the list of scores, they were discussed by looking at 
the scores for each component. Average scores were used when there were differences in scoring results. Students' scores of writing are shown in Appendix A. The mean of students' scores in the three topics was used as the scores of the students' proficiency in writing, while students' scores of each of the topic were used as the scores across topic variety.

Table 1. Scoring Arrangement

\begin{tabular}{llll}
\hline No & Topic & \multicolumn{2}{l}{ Rater (Number of essay) } \\
\hline 1 & General topic & Rater 2 (52) & Rater 3 (52) \\
2 & Personal topic & Rater 1 (52) & Rater 3 (52) \\
3 & Academic topic & Rater 1 (52) & Rater 2 (52) \\
\hline
\end{tabular}

In addition to the administration of the essay writing assignments to gain scores of topic variety and proficiency in writing, a questionnaire was distributed to collect scores of students' apprehension. The most familiar questionnaire on writing apprehension was the one developed by Daly and Miller (1975). Previous studies, for instance, Huwari and Aziz (2011), Ayodele and Akinlana (2012), and Kara (2013) adopted it. To meet the needs of EFL students in Indonesia, this study adapted the Daly and Miller (1975) writing apprehension questionnaire including three dimensions. First, the unwillingness to communicate dimension covered the variables of anxiety about writing in general. Second, the communication apprehension dimension covered the self-report on positive attitudes toward writing and self-report on negative attitudes toward writing variables. Third, receiver apprehension dimension covered the variables of evaluation of writing (teacher, professional, and peer evaluation).

The questionnaire originally consisted of twenty six items. The results of instrument developmental stages were conducted by validating and trying out to thirty students at another university with similar characteristics and they showed that one of the items was invalid; therefore, twenty five items were used in this study. The questionnaire used a 5 Likert-type scale ranging from (1) strongly agree to (5) strongly disagree. The questionnaire scores ranging from 25 to 125 . The scores were classified into three levels of apprehension: 93-125 (low), 58-92 (moderate), and 25-57 (high). Most of the students were in the moderate level, showing that they did not experience an unusual level of writing apprehension.

All of the 52 students from Class A and Class B completed the apprehension questionnaire. From the results of analysis of the questionnaire, it was found that there were 16 students who had low apprehension (meaning that they had low anxiety) and 36 students who had moderate apprehension (meaning that they had moderate level of anxiety), and none of the students had high apprehension level. Students' apprehension scores are shown in Appendix A along with their writing scores. Students' apprehension scores are divided into low and moderate levelsas shown in Appendix B. Students' writing scores in three different topics are shown in Appendix C. These topic variety scores were 
compared to answer the third research question. The correlational analyses were carried out in the SPSS program.

\section{Results}

The results of this study are presented following the order of the research questions. The first description of the findings of this this study deals with the relation between Indonesian EFL students' apprehension and proficiency in writing. The second description shows the difference between Indonesian EFL students' proficiency in writing across apprehension levels. Lastly, the third description of the findings focuses on the difference among Indonesian EFL students' proficiency in writing across topic variety namely general topic, personal topic, and academic topic.

\subsection{The relation between Indonesian EFL Students'Apprehension and Proficiency in Writing}

To answer the first research question, students' scores in the writing apprehension questionnaire were listed along with their proficiency scores in writing. In order to see the correlation between Indonesian EFL students' apprehension and proficiency in writing, the normality of the data was checked using Kolmogorov-Smirnov test. The test revealed that the data in terms of students' apprehension scores and writing scores were normally distributed. Further analysis was run using Pearson product moment correlation test to seek the correlation between students' apprehension level and their proficiency in writing. The result of the analysis of correlations is shown in Table 2.

Table 2. Correlations between Indonesian EFL Students' Apprehension and Proficiency in Writing

\begin{tabular}{llll}
\hline & & Apprehension & Proficiency in Writing \\
\hline Apprehension & Pearson Correlation & 1 & .195 \\
& Sig. (1-tailed) & & .083 \\
& $\mathrm{~N}$ & 52 & 52 \\
Proficiency in Writing & Pearson Correlation & .195 & 1 \\
& Sig. (1-tailed) & .083 & \\
& $\mathrm{~N}$ & 52 & 52 \\
\hline
\end{tabular}

Table 2 shows that all of the 52 students' scores on two variables have been computed and the result shows that the coefficient correlation is .195. This coefficient correlation is not statistically significant as indicated by the $p$-value of .083 which is greater than the level of significance $(p>.05)$. This indicated that there was no significant relation between students' apprehension and their proficiency in writing. In other words, students' apprehension level was not related to their proficiency in writing. 
3.2 The Difference between Indonesian EFL Students' Proficiency in Writing across Apprehension

Levels

The second research question aimed to compare students' proficiency in writing across different apprehension levels. To answer the second research question, students' proficiency scores in writing were compared across apprehension levels: low apprehension and medium apprehension. From the descriptive statistics presented in Table 3, it was found that the mean score of students of low apprehension level was 75.81 and the mean score of students of medium apprehension level was 77.08. Slightly, the mean score of the students of medium apprehension level was higher than the mean score of the students of low apprehension level. However, the final decision to see the difference between the two groups is determined by the statistical analysis.

Table 3. The Descriptive Statistics of the Scores of the Low and Medium Apprehension Students

\begin{tabular}{llllllllll}
\hline & & & \multicolumn{2}{c}{ Std. } & Std. & \multicolumn{2}{c}{$\mathbf{9 5 \%}$ Confidence Interval for Mean } & \\
\cline { 7 - 8 } Level & $\mathbf{N}$ & Mean & Deviation & Error & Lower Bound & Upper Bound & Minimum & Maximum \\
\hline Low & 16 & 75.812 & 4.593 & 1.148 & 73.365 & 78.259 & 67.00 & 83.00 \\
Medium & 36 & 77.083 & 3.083 & .513 & 76.040 & 78.126 & 71.00 & 83.00 \\
Total & 52 & 76.692 & 3.616 & .501 & 75.685 & 77.699 & 67.00 & 83.00 \\
\hline
\end{tabular}

The statistical analysis was carried out to compare students' scores across apprehension levels. A normality test was used-Kolmogorov-Smirnov test—and a homogeneity test-Levene test- to determine the statistical computation to be used. The tests showed that the data were normally distributed and homogenous. ANOVA one-way was employed to see the difference in terms of proficiency in writing between students with low and medium apprehension levels. Table 4 depicts the summary of the ANOVA one-way result of the second research question.

Table 4. Comparison of Scores of Writing between the Low and Medium Apprehension Levels

\begin{tabular}{llllll}
\hline & Sum of Squares & df & Mean Square & F & Sig. \\
\hline Between Groups & 17.889 & 1 & 17.889 & 1.378 & .246 \\
Within Groups & 649.188 & 50 & 12.984 & & \\
Total & 667.077 & 51 & & & \\
\hline
\end{tabular}

Table 4 shows that the $p$-value is higher than the level of significance $(.246>.05)$. This indicates that there was no significant difference in the proficiency in writing between students of low apprehension level and those of medium apprehension level. 


\subsection{The Difference among Indonesian EFL Students' Proficiency across Topic Variety}

The third research question was aimed at finding differences among Indonesian EFL students' proficiency in writing across topic variety. To this end, the scores of the students' proficiency in writing in the three different topics were compared. Table 5 shows the descriptive statistics of the students' scores in writing the three topics. Generally, the mean scores of general topic $(\bar{x}=78.03)$ and personal topics $(\bar{x}=77.21)$ were higher than the students' scores in writing academic topic $(\bar{x}=$ 74.82).

Table 5. The Descriptive Statistics of Scores of Writing based on Topic Variety: General Topic (GT), Personal Topic (PT), and Academic Topic (AT)

Std. Std. $\quad 95 \%$ Confidence Interval for Mean

\begin{tabular}{lllllllll} 
Topics & N & Mean & \multicolumn{3}{c}{ Deviation Error Lower Bound } & Upper Bound & \multicolumn{2}{c}{ Minimum Maximum } \\
\hline GT & 52 & 78.038 & 3.319 & .460 & 77.114 & 78.962 & 70.00 & 84.00 \\
PT & 52 & 77.211 & 3.927 & .544 & 76.118 & 78.305 & 66.00 & 85.00 \\
AT & 52 & 74.826 & 5.120 & .710 & 73.401 & 76.252 & 65.00 & 84.00 \\
Total & 156 & 76.692 & 4.381 & .350 & 75.999 & 77.385 & 65.00 & 85.00 \\
\hline
\end{tabular}

Similar to the previous research question analyses, the normality and homogeneity of the scores from three topics were checked. Further analysis using ANOVA one-way was run to find out the difference of the scores among the three topics namely general topic, personal topic, and academic topic. The result is shown in Table 6 .

Table 6. Comparisons of Scores of Writing between the Low and Medium Apprehension Levels

\begin{tabular}{llllll}
\hline & Sum of Squares & df & Mean Square & F & Sig. \\
\hline Between Groups & 289.192 & 2 & 144.596 & 8.236 & .000 \\
Within Groups & 2686.038 & 153 & 17.556 & & \\
Total & 2975.231 & 155 & & & \\
\hline
\end{tabular}

Table 6 shows that the $p$-value was lower than the significant level $(.000<.05)$. This implied that the scores from the three topics given differed significantly. Therefore, a pos hoc analysis was carried out as the follow up of the analysis of the third research question. The result of the comparison of the scores in general topic, personal topic, and academic topic is shown in Table 7. 
Table 7. Comparisons of Scores of Writing based on Topic Variety: General Topic (GT), Personal Topic (PT), and Academic Topic (AT)

\begin{tabular}{|c|c|c|c|c|c|c|c|c|}
\hline \multirow[t]{2}{*}{ (I) Topic } & & \multirow[t]{2}{*}{ (J) Topic } & & Mean & \multirow[t]{2}{*}{ Std. Error } & \multirow[t]{2}{*}{ Sig. } & \multicolumn{2}{|c|}{ 95\% Confidence Interval } \\
\hline & & & & Difference (I-J) & & & Lower Bound & Upper Bound \\
\hline \multirow{6}{*}{ dimension2 } & \multirow[t]{2}{*}{ GT } & \multirow{2}{*}{ dimension3 } & PT & .826 & .821 & .316 & -.796 & 2.450 \\
\hline & & & AT & $3.211^{*}$ & .821 & .000 & 1.588 & 4.834 \\
\hline & \multirow{2}{*}{ PT } & \multirow{2}{*}{ dimension3 } & GT & -.826 & .821 & .316 & -2.450 & .796 \\
\hline & & & AT & $2.384^{*}$ & .821 & .004 & .761 & 4.008 \\
\hline & \multirow[t]{2}{*}{ AT } & \multirow{2}{*}{ dimension3 } & GT & $-3.211^{*}$ & .821 & .000 & -4.834 & -1.588 \\
\hline & & & PT & $-2.384^{*}$ & .821 & .004 & -4.008 & -.761 \\
\hline
\end{tabular}

* The mean difference is significant at the .05 level.

Table 7 describes the comparisons among the three topics. There were significant differences between students' proficiency in writing general topic and academic topic $(.000<.05)$ and between their proficiency in writing personal topic and academic topic $(.004<.05)$. However, the results indicate that students' proficiency in writing general topic was not significantly different from their proficiency in writing personal topic $(.316>.05)$. All in all, students' proficiency in writing academic topic differs significantly from other topics. This showed that students had difficulty in writing academic topics compared to writing general and personal topics.

\section{Discussion}

This study revealed the relation between Indonesian EFL students' apprehension, topic variety, and proficiency in writing. Two of the non-linguistic factors which particularly cover apprehension as the affective factor and topic variety as the cognitive factor were the foci of this study. Previous researchers, Asmari (2013) and Al-Sawalha and Chow (2012), found that apprehension was highly correlated with writing performance. In contrast, the first result of this study pointed out that there was no significant relation between students' apprehension and their proficiency in writing. The scores on two variables, namely, apprehension and proficiency in writing, showed that the coefficient correlation was very low (.195) and the $p$-value of .083 was greater than the level of significance ( $p>.05)$. In addition, the second result of this study indicated that there was no significant difference in the proficiency in writing between students of low apprehension level and those of medium apprehension level. It was shown by the $p$-value which is higher than the level of significance $(.246>.05)$.

These contradictory results are caused by the influence of different observed apprehension levels. The common apprehension level categories fall within low, moderate, and high levels as can be seen on the studies by Ayodele and Akinlana (2012) and Al-Sawalha and Chow (2012) and within the contrast level (high and low levels) for instance in Asmari (2013) study. Unlike previous studies, this study has 
mainly students with moderate apprehension level. In addition, the two levels involved in this study, namely the low and moderate levels, were not far different each other. Therefore, this study could not provide enough empirical evidence that apprehension was related to proficiency in writing. Nevertheless, it confirms Daly and Miller's (1975) classification on moderate apprehension level in that most students whose score fall in this range do not experience a significantly unusual level of writing apprehension. On the contrary, Asmari (2013) found strong relation between apprehension and writing performance on two contrast apprehension levels namely the high and low apprehension levels. Other study, Al-Sawalha and Chow (2012) found that writing apprehension level affected the frequency and type of writing strategies.

Different from the previous studies, this study was in line with the results of Choi's (2013) study. Choi's (2013) study showed that the correlation between apprehension and writing performance was also absent. Employing an English Writing Anxiety Scale (EWAS) adapted from Lee (2005), he uncovered three grounds of the significant correlation absence. The first was unavoidable omission of the data. The second was lack of a more detailed scoring rubric employed in his study. The last was limited type of writing, focusing on free writing assignments only. It was established that this type of writing was one of the least anxiety provoking, the least-overwhelming, and the lower stake genres. The students in high apprehension could perform well in this writing. Even though this finding was technically different in some ways, like the number of participants, the use of writing apprehension measurement, and the scoring rubric, Choi (2013) discovery on the limited type of writing is related to the third research result of this study, which is topic variety.

While Chow (2013) found that free writing assignments only made the students feel less anxious, this study focuses on the comparisons of general, personal, and academic topics. As it was pointed out that among the three topics, the general and academic topics $(.000<.05)$ as well as personal and academic topics $(.004<.05)$ resulted significant differences, while general and personal topics $(.316>.05)$ was not significantly difference, the presence of topic variety influences the students' proficiency in writing. Writing under academic topic places the students into different difficulty compared to the other two topics namely general and personal ones. This result conforms Kara's (2013) and D'Mello's (2014) studies. Kara's (2013) study in particular found that the students' inability in writing under academic topics were caused by their limited strategies in organizing ideas, gathering information, and combining ideas. In addition, Kara uncovered that the experience of frustration and anger were found on the academic topic.

This study was consistent to D'Mello's (2014) study. He focused on three such prompts: two topics on argumentative prompts which may or may not be controversial and the other topic on personal reflection prompt which asked the writers to describe a personal experience. D'Mello (2014) found that emotions were tied to topics and affected the writing quality. He further stated that students who write about specific emotional events facilitate their experience of the emotions. Therefore, the difference on the general, personal, and academic topics in this study was confirmed. The students felt more into general 
and personal topics due to their existing or background knowledge. Meanwhile, writing academic topic involves less emotional experience compared to general and personal topics. In the field of assessment itself, Hult (1987) suggested sufficient consideration in given topics on writing due to the influence that may cause minor variation in wording and lead to students' writing performance and proficiency.

The result of the present study is different from that of Nugraheni (2016) who found that topic variety has no significant effect in writing. The two studies involved Indonesian EFL students who were asked to write in three different topics: general, personal, and academic (or field-discipline, in Nugraheni's term). In fact, the students involved in the two studies were from different majors. While the present study involved EFL students from the English deparment, Nugraheni study involved students from Accounting department who took English for a Specific Purpose (ESP) which is accounting. With limited credits for ESP course in the Accounting department, the insignificant differences of the students' achievement in the three topics might be caused by the linguistic problems they have in their ESP learning. Thus, regardless of the topics assigned to the Accounting department students, they still need to improve their proficiency in general English in order to write better essays. Meanwhile, the students in this study who come from English department have better English proficiency than those Accounting department students.

\section{Conclusion}

Drawing on the aforementioned results and discussion, it was concluded that, first, there was insignificant relation between students' apprehension and their proficiency in writing. This was because the observed level of the apprehension was dominated by the medium apprehensive students. Second, the first conclusion is related to the second focus of this study that there was insignificant difference in the proficiency in writing between students of low and medium apprehension levels. It was apparent that this result was caused by the influence of different observed apprehension levels. The contrast between high and low apprehension levels resulted negative correlation; whereas focusing on the moderate and low apprehension levels resulted in insignificant relation between apprehension and students' proficiency in writing. Future researchers are suggested having detail and thorough investigation through a factorial quasi-experimental design to seek how each apprehension level influence students' proficiency in writing. Third, it was found that there was significant difference among Indonesian EFL students' proficiency across topic variety. It was established that writing about academic topic is the most difficult compared to general and personal topics. The challenges in academic topic and the emotional involvement in general and personal topics influenced the difference among these topics. It could be deduced from this study that there might be some underlying factors that might swift the writing apprehension relation to proficiency in writing, namely the levels in the apprehension itself. In addition, there are other factors namely topic variety that influences the students' proficiency in writing. Therefore, teachers are suggested not to consider students' apprehension level in a negative way and they might consider topic variety as a way to help students write more easily. 


\section{References}

Allwright, R. L. (1998). Affective filter [a definition]. In K. Johnson, \& H. Johnson (Eds.), Encyclopedic dictionary of applied linguistics (p. 5). Oxford: Blackwell.

Al-Sawalha, A. M. S., \& Chow, T. V. F. (2012). The effects of writing apprehension in English on the writing process of Jordanian EFL students at Yarmouk university. International Interdisciplinary Journal of Education, 1(1), 6-14.

Amiri, M., \& Ghonsoonly, B. (2015). The relationship between English learning anxiety and the students' achievement on examinations. Journal of Language Teaching and Research, 6(4), 855-865. http://dx.doi.org/10.17507/jltr.0604.20

Asmari, A. (2013). Investigation of writing strategies, writing apprehension, and writing achievement among Saudi EFL-major students. Canadian Center of Science and Education, 6(11), 130-143. http://dx.doi.org/10.5539/ies.v6n11p130

Ayodele, K. O., \& Akinlana, T. (2012). Writing apprehension and Nigerian undergraduates' interest in dissertation's writing: The moderator effects of self-efficacy, emotional intelligence and academic optimism. The African Symposium, 12(1), 46-56.

Bobanovic, M. K. (2016). Investigation of university students' efl writing apprehension: A longitudinal study in Croatia. Review of Innovation and Competitiveness, 2(1), 5-18.

Cahyono, B. Y., \& Widiati, U. (2011). The teaching of English as a foreign language in Indonesia. Malang: State University of Malang.

Choi, S. (2013). Language anxiety in second language writing: Is it really a stumbling block? Second Language Studies, 31(2), 1-42.

Daly, J. A., \& Miller, M. D. (1975). The empirical development of an instrument to measure Writing Apprehension. Research in the Teaching of English, 9(3), 242-249.

D’Mello, S. (2014). Emotions while writing about emotional and non-emotional topics. Motivation and Emotion, 38(1), 140-156. http://dx.doi.org/10.1007/s11031-013-9358-1

Ellis, R. (2001). The study of second language acquisition (8th ed.). Oxford: Oxford University Press.

Harmer, J. (2004). How to teach writing. Edinburgh Gate, Essex: Pearson Education.

Hartfiel, V. F., Jacobs, H. L., Zinkgraft, S. A., Wormuth, D. R., \& Hughey, J. B. (1985). Learning ESL composition. Rowley, MA: Newbury House.

Henter, R. (2014a). Developing metacognitive skills as a foundation of learning a foreign language. Romanian Journal of Experimental Applied Psychology, 5(1), 48-57.

Henter, R. (2014b). Affective factors involved in learning a foreign language. Procedia-Social and Behavioral Sciences, 373-378. http://dx.doi.org/10.1016/j.sbspro.2014.03.274

Hult, C. A. (1987). Assessment topics: The importance of the rhetorical frame. Writing Program Administration, 10(3), 19-28.

Huwari, I. F., \& Aziz, N. H. A. (2011). Writing apprehension in English among Jordanian postgraduate students at Universiti Utara Malaysia (UUM). Academic Research International, 1(2), 190-198. 
Jain, Y., \& Sidu, G. K. (2013). Relationship between anxiety, attitude and motivation of tertiary students in learning English as a second language. Procedia-Social and Behavioral Sciences, 90(1), 114-123.

Ji, X. (2011). Topic effects on writing performance: What do students and their writing tell us? The Journal of Asia TEFL, 8(1), 23-38.

Kara, S. (2013). Writing anxiety: A case study on students' reasons for anxiety in writing classes. Anadolu Journal of Educational Sciences International, 3(1), 103-111.

Khezrlou, S. (2012). The relationship between cognitive and metacognitive strategies, age, and level of education. The Reading Matrix, 12(1), 50-61.

Lightbown, P. M., \& Spada, N. (2013). How languages are learned. Oxford: Oxford University Press.

Lubold, S. L., Forbes, S., \& Steveson, I. (2016). The effect of topic selection on writing fluency among Japanese high school students. Indonesian Journal of Applied Linguistics, 5(2), 231-241.

Nugraheni, D. A. (2016). Students' writing performances across different topic scopes: General, personal, and field-discipline. Unpublished Master's Thesis. Malang, Indonesia: State University of Malang.

Ong, J., \& Zhang, L. J. (2013). Effects of the manipulation of cognitive processes on EFL writers' text quality. Tesol Quarterly, 47(2), 375-398.

Oshima, A., \& Hogue, A. (2006). Writing academic English. White Plains, NY: Pearson.

Oshima, A., \& Hogue, A. (2007). Introduction to academic writing. New York: Pearson Education.

Oxford, R. L. (1990): Language learning strategies: What every teacher should know. Boston: Heinle \& Heinle.

Richards, J. C., \& Renandya, W. A. (2002). Methodology in language teaching: An anthology of current practice. Cambridge: Cambridge University Press.

Smalley, R. L., Ruetten, M. K., \& Kozyrev, J. R. (2001). Refining composition skills: Rhetoric and grammar for ESL students. Boston, MA: Heinle \& Heinle.

Weigle, S. C. (2002). Assessing writing. Cambridge: Cambridge University Press.

\section{Appendix A}

The Students' Scores of Apprehension (SA) and Scores of Writing (SW) from Class A ( $N=26)$ and Class $B(N=26)$

\begin{tabular}{llllll}
\hline Student/Class/No & SA & SW & Student/Class/No & SA & SW \\
\hline Pur (A1) & 75 & 77 & Fir (B1) & 100 & 78 \\
Feb (A2) & 78 & 71 & Put (B2) & 89 & 77 \\
Bus (A3) & 89 & 76 & Nab (B3) & 88 & 83 \\
Lar (A4) & 111 & 81 & Aje (B4) & 90 & 81 \\
Sya (A5) & 88 & 77 & Zah (B5) & 90 & 78 \\
\hline
\end{tabular}




\begin{tabular}{llllll}
\hline Roh (A6) & 102 & 69 & Kar (B6) & 83 & 80 \\
Agu (A7) & 85 & 76 & Dwi (B7) & 101 & 82 \\
Sed (A8) & 97 & 67 & Pra (B8) & 74 & 76 \\
Pen (A9) & 95 & 78 & Nui (B9) & 89 & 78 \\
Afi (A10) & 65 & 78 & Hid (B10) & 105 & 75 \\
Ram (A11) & 88 & 74 & Isa (B11) & 96 & 73 \\
Fad (A12) & 78 & 71 & Via (B12) & 91 & 76 \\
Sar (A13) & 87 & 76 & Saa (B13) & 78 & 75 \\
Izz (A14) & 80 & 76 & Res (B14) & 95 & 83 \\
Rus (A15) & 77 & 76 & Ali (B15) & 65 & 74 \\
Har (A16) & 85 & 79 & Erf (B16) & 106 & 79 \\
Abd (A17) & 74 & 79 & Taf (B17) & 99 & 81 \\
Sal (A18) & 95 & 79 & Ayu (B19) & 88 & 77 \\
Gad (A19) & 70 & 74 & Des (B19) & 88 & 78 \\
Saf (A20) & 76 & 76 & Hab (B20) & 101 & 81 \\
Kus (A21) & 78 & 74 & Nug (B21) & 101 & 79 \\
Roh (A22) & 80 & 73 & Nad (B22) & 90 & 83 \\
Azi (A23) & 88 & 73 & Agr (B23) & 88 & 77 \\
Sof (A24) & 83 & 72 & Yon (B24) & 72 & 80 \\
Yud (A25) & 104 & 78 & Wiy (B25) & 90 & 76 \\
Ari (A26) & 97 & 69 & Kam (B26) & 79 & 79 \\
Mean & 86 & 75 & Mean & 93 & 78 \\
\hline
\end{tabular}

\section{Appendix B}

The Students' Scores of Apprehension (SA) and Scores in Writing (SW) Based on the Apprehension Levels

\begin{tabular}{llllll}
\hline \multicolumn{2}{l}{ Low Apprehension Level } & \multicolumn{5}{l}{ Medium Apprehension Level } \\
\hline Student/Class/No & App Score & Wrt Score & Student/Class/No & App Score & Wrt Score \\
\hline Erf (B16) & 106 & 79 & Via (B12) & 91 & 76 \\
Lar (A4) & 111 & 81 & Aje (B4) & 90 & 81 \\
Hid (B10) & 105 & 75 & Zah (B5) & 90 & 78 \\
Yud (A25) & 104 & 78 & Nad (B22) & 90 & 83 \\
Roh (A6) & 102 & 69 & Wiy (B25) & 90 & 76 \\
Dwi (B7) & 101 & 82 & Bus (A3) & 89 & 76 \\
Hab (B20) & 101 & 81 & Put (B2) & 89 & 77 \\
Nug (B21) & 101 & 79 & Nui (B9) & 89 & 78 \\
\hline
\end{tabular}




\begin{tabular}{|c|c|c|c|c|c|}
\hline Fir (B1) & 100 & 78 & Sya (A5) & 88 & 77 \\
\hline Taf (B17) & 99 & 81 & $\operatorname{Ram}(\mathrm{A} 11)$ & 88 & 74 \\
\hline Sed (A8) & 97 & 67 & Azi (A23) & 88 & 73 \\
\hline Ari (A26) & 97 & 69 & $\mathrm{Nab}$ (B3) & 88 & 83 \\
\hline Isa (B11) & 96 & 73 & Ayu (B19) & 88 & 77 \\
\hline Pen (A9) & 95 & 78 & Des (B19) & 88 & 78 \\
\hline Sal (A18) & 95 & 79 & $\operatorname{Agr}(\mathrm{B} 23)$ & 88 & 77 \\
\hline \multirow[t]{21}{*}{$\operatorname{Res}(\mathrm{B} 14)$} & 95 & 83 & Sar (A13) & 87 & 76 \\
\hline & & & Agu (A7) & 85 & 76 \\
\hline & & & Har (A16) & 85 & 79 \\
\hline & & & Sof (A24) & 83 & 72 \\
\hline & & & Kar (B6) & 83 & 80 \\
\hline & & & Izz (A14) & 80 & 76 \\
\hline & & & Roh (A22) & 80 & 73 \\
\hline & & & Kam (B26) & 79 & 79 \\
\hline & & & Feb (A2) & 78 & 71 \\
\hline & & & Fad (A12) & 78 & 71 \\
\hline & & & Kus (A21) & 78 & 74 \\
\hline & & & Saa (B13) & 78 & 75 \\
\hline & & & Rus (A15) & 77 & 76 \\
\hline & & & Saf (A20) & 76 & 76 \\
\hline & & & Pur (A1) & 75 & 77 \\
\hline & & & Abd (A17) & 74 & 79 \\
\hline & & & Pra (B8) & 74 & 76 \\
\hline & & & Yon (B24) & 72 & 80 \\
\hline & & & Gad (A19) & 70 & 74 \\
\hline & & & Afi (A10) & 65 & 78 \\
\hline & & & Ali (B15) & 65 & 74 \\
\hline Mean & 100.31 & 77 & Mean & 82.11 & 76.56 \\
\hline
\end{tabular}

\section{Appendix C}

The Students' Scores of Writing across Topic Variety: General Topic (GT), Personal Topic (PT), Academic Topic (AT) $(\mathbf{N}=\mathbf{5 2})$

\begin{tabular}{llllllll}
\hline Student/Class/No & GT & PT & AT & Student/Class/No & GT & PT & AT \\
\hline Dwi (B7) & 84 & 81 & 82 & Kam (B26) & 79 & 82 & 77 \\
Res (B14) & 84 & 83 & 83 & Pur (A1) & 78 & 81 & 72 \\
\hline
\end{tabular}




\begin{tabular}{|c|c|c|c|c|c|c|c|}
\hline $\mathrm{Nad}(\mathrm{B} 22)$ & 84 & 82 & 84 & Nui (B9) & 78 & 75 & 82 \\
\hline Pen (A9) & 83 & 78 & 73 & Hid (B10) & 78 & 75 & 73 \\
\hline $\mathrm{Nab}$ (B3) & 83 & 85 & 82 & Zah (B5) & 77 & 77 & 79 \\
\hline Kar (B6) & 83 & 77 & 81 & Pra (B8) & 77 & 74 & 76 \\
\hline Lar (A4) & 82 & 81 & 80 & Via (B12) & 77 & 77 & 74 \\
\hline Har (A16) & 81 & 79 & 76 & Ayu (B18) & 77 & 78 & 75 \\
\hline Yud (A25) & 81 & 79 & 75 & Wiy (B25) & 77 & 77 & 75 \\
\hline Saa (B13) & 81 & 69 & 76 & Sya (A5) & 76 & 81 & 73 \\
\hline Abd (A17) & 80 & 80 & 77 & Gad (A19) & 76 & 77 & 69 \\
\hline Sal (A18) & 80 & 80 & 78 & Saf (A20) & 76 & 78 & 73 \\
\hline Fir (B1) & 80 & 75 & 80 & Sof (A24) & 76 & 72 & 68 \\
\hline Erf (B16) & 80 & 80 & 77 & Isa (B11) & 76 & 73 & 71 \\
\hline Hab (B20) & 80 & 81 & 81 & $\operatorname{Ram}(\mathrm{A} 11)$ & 75 & 79 & 68 \\
\hline Nug (B21) & 80 & 79 & 77 & Fad (A12) & 75 & 74 & 65 \\
\hline Yon (B24) & 80 & 78 & 82 & Izz (A15) & 75 & 78 & 74 \\
\hline Bus (A3) & 79 & 78 & 70 & Kus (A21) & 75 & 77 & 69 \\
\hline Agu (A7) & 79 & 74 & 74 & Roh (A22) & 75 & 75 & 68 \\
\hline Afi (A10) & 79 & 80 & 76 & Ali (B15) & 75 & 75 & 71 \\
\hline Sar (A13) & 79 & 78 & 70 & Rus (A15) & 74 & 80 & 74 \\
\hline Put (B2) & 79 & 74 & 78 & Azi (A23) & 74 & 74 & 71 \\
\hline Aje (B4) & 79 & 83 & 80 & Feb (A2) & 73 & 74 & 67 \\
\hline Taf (B17) & 79 & 82 & 81 & Roh (A6) & 71 & 69 & 66 \\
\hline Des (B19) & 79 & 76 & 80 & Ari (A26) & 71 & 69 & 67 \\
\hline \multirow[t]{2}{*}{ Agr (B23) } & 79 & 76 & 75 & Sed (A8) & 70 & 66 & 66 \\
\hline & & & & Mean & 78 & 77 & 75 \\
\hline
\end{tabular}

